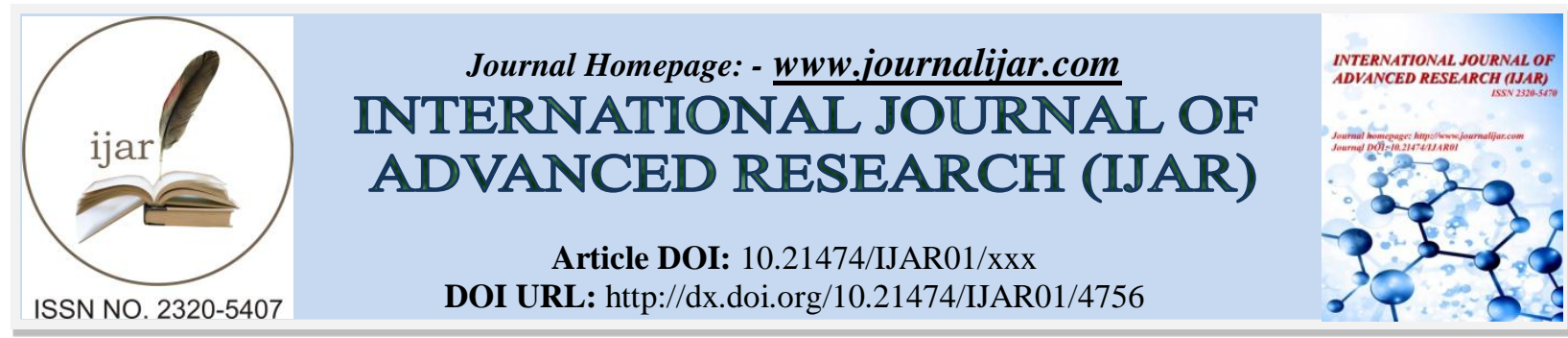

RESEARCH ARTICLE

\title{
TREATMENT OF DEPRESSION IN ELDERLY.
}

\section{Bhavya K Bairy ${ }^{1}$ and Laxminarayana K Bairy ${ }^{2}$.}

1. Department of Psychiatry, St. John's Medical College Hospital, Bengaluru, Karnataka, India.

2. Department of Pharmacology, RAK College of Medical Sciences, RAK Medical and Health Sciences University, Ras Al Khaimah, UAE.

\section{Manuscript Info}

Manuscript History

Received: 5 May 2017

Final Accepted: 7 June 2017

Published: July 2017

Key words:-

Major depression, elderly population, treatment.

\begin{abstract}
Depression is one of the common health problem in elderly population. It significantly affects patients, families, and communities. A knowledge of predisposing and precipitating factors can help identify patients in need of treatment using tools such as the Geriatric Depression Scale. Proper medication and regular follow up are the two important aspects of management of depression in the elderly. Choice of an antidepressant drug should be based on best side effect profile and lowest risk of drug-drug interaction. The altered pharmacokinetics of antidepressants in the elderly should be borne in mind while selecting the drug and its dose. Electroconvulsive therapy is recommended in severe, psychotic, or refractory depression in the elderly.
\end{abstract}

Copy Right, IJAR, 2017, All rights reserved.

\section{Introduction:-}

About 15 to $20 \%$ of elderly (Above sixty-five years) population suffer from major depression.[1]. The World Health Organization (WHO) has ranked depression as the 4th leading cause of disability worldwide [2] and projects that by 2020, it will be the second leading cause [3]. Depression can lead to various consequences such as loss of appetite, decreased work capacity and the most important is increased chances of death by suicide. In elderly population the presentation of depression may not be typical because of infirmity and comorbid conditions [4]. In spite of introduction of many new drugs, optimal outcomes might also be challenging to obtain due to infirmity in older patients. This article mainly includes pharmacologic treatment, titration of dose, and treatment of unresponsive cases.

\section{How does depression in the elderly differ from depression in younger adults?}

Elderly patients are less likely to endorse cognitive-affective symptoms of depression, including dysphoria and worthlessness/guilt, than are younger adults [5]. Sleep disturbance, fatigue, psychomotor retardation, loss of interest in living, and hopelessness about the future may be more prevalent in late-life depression than in depression in younger or middle-aged adults [6]. Subjective complaints of poor memory and concentration are also common among depressed older adults. Slower cognitive processing speed and executive dysfunction are frequent findings from objective testing [7]. Unlike in young individuals, in the elderly, depression often occurs with other comorbid conditions and lasts longer. Depression in the elderly often increases the risk of cardiac diseases and an increased risk of death from illness.

Corresponding Author: - Bhavya K Bairy. 


\section{Etiology and risk factors}

Genetic factor, stressful life events, neuroticism and previous depression are the main risk factors in younger age group, whereas cardiovascular disorders, stressful life events, insomnia, activity curtailment, cognitive impairment and neuropathology are the main risk factors in the elderly [8].

Genetic factor contributes mainly earlier in the lifespan rather than later. Kindler et al did a study using twin registry and reported that heritability was $42 \%$ for females and $29 \%$ for males, with no difference by birth cohort [9]. Risk of major depression in the co-twin was higher when age of onset was earlier in the depressed twin, with first onset older than age 35 not meaningfully affecting risk of depression for the co-twin [10].

Non-genetic biological risk factors for depression play a major role in old age. This is because of age-related changes that make them more common in older adults. The biological risk factors are hormone related. The biological status may also interfere with drug treatment. It is well known fact that depressive reaction can be precipitated by any chronic disease. More commonly involved conditions that are strongly associated with depression include cardiovascular and cerebrovascular disease and neurological conditions. Chronic infections or malignancies may also cause depression. It has been reported that depression can lead to diabetes mellitus. Both hypothyroidism and hyperthyroidism are associated with high incidence of depression [11].

It is observed that there is substantial co-morbidity for major depression and dementia, and differential diagnosis is often challenging. Dementia in together with major depression may not completely reverse as the depression subsides [12]. Patients with late onset major depression with cognitive impairment are especially at risk of developing Alzheimer's disease(AD), with as many as $40 \%$ developing dementia within three to five years $[13,14]$. Among other neurological disorders the incidence of major depression is highest among stroke patients (20-25\%) and intermediate among those with Parkinson's disease (15-20\%) compared to 10-15\% among those with AD $[15,16]$. Anxiety disorder in young age is definitely a risk factor for late life depression [17]. Whenever anxiety coexists with depression, the latter is more severe, persistent, and difficult to treat [18].

For depression in elderly, sleep disturbance is a risk factor for both onset and persistence of depression. Acute onset insomnia may be conditioned or may be maintained by a person's compensatory behaviors, such that it takes on a chronic course independent of the original precipitating factors. Treating insomnia along with treatment of depression will benefit in management of depression [19].

Old age depression is not closely related to social risk factor such as stressful life events and inadequate social or practical support. However, the number of stressful life events a person experiences has been associated with depression in late life, as at other ages [20], although the relative frequency of different types of events may change with age. Examples of stressful events are financial difficulties, bereavement, a new physical illness or disability in self or family member, change in living situation, and interpersonal conflict. Socioeconomic factors definitely contribute to late life depression. Deterioration in financial status is among the most frequently-endorsed stressful life events experienced by older adults [21]. Elderly people who have financial problem are more likely to experience persistent depressive symptoms, consistent with the chronic nature of the stressors associated with low income, including financial strain and exposure to unsafe and unstable environments [22].

One may be surprised to know that most older adults do not experience depression. This is mainly because: (a) the importance of resources-health, cognitive function, socioeconomic status; (b) the idea that the life experiences of older adults have taught them psychological strategies and ways to use social support to manage their health-related stressors; and (c) the role of meaningful engagement, whether in social activities, volunteer work, or religion [23].

Suicide is a tragic potential outcome of depression in late life. Bostwick and Pankratz reported that nearly four percent of individuals with an inpatient admission for depression will die by suicide [24], however most people who do die by suicide were depressed. Furthermore, suicide among older adults is more likely to be associated with depression than suicide at any other age [25]. This fact is particularly troubling since depression can be effectively treated in late life

\section{Treatment:-}

The main objective of treatment is to improve in symptoms using a validated scale (eg, 50\% reduction on the Hamilton Depression Rating Scale or the Patient Health Questionnaire-9)(26). However, the ideal objective should 
be remission of symptoms[27]. There are several treatment options available for depression. They include pharmacotherapy, psychotherapy or counselling, or electroconvulsive therapy or other newer forms of brain stimulation (such as repetitive transcranial magnetic stimulation (rTMS)). Sometimes, a combination of these treatments may be used [28].

The pharmacotherapy of depression in the elderly is not the same as in younger patients. It differs in two key points. First and foremost is that older patients are more prone to the side-effects of antidepressant drugs and experience greater difficulty in tolerating doses that are of therapeutic value [29]. Another point is, older patients may take longer to respond to antidepressant medication than younger patients [30]. Since elderly people are more sensitive to medicines, doctors may prescribe lower doses at first. In general, the length of treatment for depression in the elderly is longer than it is in younger patients.

A proper history regarding the elderly patients' previous response to treatment, the type of depression, patient's other medical problems, patient's other medications, and potential risk of overdose is very much crucial while selecting an antidepressant in these patients [1]. While treating depression due to medical illness it is important to see that the antidepressants improve depression, and at the same time will not worsen medical condition or cause adverse effects [31]. To give an example, antidepressants with high anticholinergic property can worsen disease like diabetes mellitus, Alzheimer's dementia, Parkinson's disease and cardiovascular problems which are common in elderly [32]. It is equally important to minimise drug-drug interactions, especially given the number of medications elderly patients are often taking. Tricyclic antidepressants are usually avoided as they are lethal in overdose.

\section{How to choose antidepressants:-}

A large number of antidepressants are available today which are proven to be efficacious in elderly patients for a major depressive episode without psychotic features. It is always to be borne in mind that selection of antidepressants is based on best side effect profile and least risk of drug interactions. The following table provides the commonly used antidepressants with recommended doses.

Table showing the commonly used antidepressants

\begin{tabular}{|c|c|c|c|c|}
\hline Drug name & $\begin{array}{l}\text { Starting } \\
\text { dose(mg/day) }\end{array}$ & $\begin{array}{l}\text { Average } \\
\text { dose(mg) }\end{array}$ & $\begin{array}{l}\text { Maximum } \\
\text { recommended } \\
\text { dose }(\mathrm{mg})\end{array}$ & Comments \\
\hline Citalopram & 10 & $20-40$ & 40 & \\
\hline Escitalopram & 5 & $10-20$ & 20 & \\
\hline Sertraline & 25 & $50-150$ & 200 & \\
\hline Bupropion & 100 & 200 & 300 & May cause seizures \\
\hline Mirtazapine & 15 & $30-45$ & 45 & \\
\hline Moclobemide & 150 & $300-600$ & 600 & $\begin{array}{l}\text { Donot combine with MAOB inhibitors } \\
\text { or Tricyclics }\end{array}$ \\
\hline Venlafaxine & 37.5 & $75-225$ & 375 & May increase blood pressure \\
\hline Desipramine & $10-25$ & $50-150$ & 300 & $\begin{array}{l}\text { Atropine like side effects, may cause } \\
\text { cardiovascular side effects, monitor } \\
\text { blood levels }\end{array}$ \\
\hline Nortriptyline & $20-25$ & $40-100$ & 200 & $\begin{array}{l}\text { Atropine like side effects, may cause } \\
\text { cardiovascular side effects, monitor } \\
\text { blood levels }\end{array}$ \\
\hline
\end{tabular}

Adopted from guidelines of the Canadian Coalition for Seniors 'Mental Health' 1

Citalopram, escitalopram and sertraline belong to the selective serotonin reuptake inhibitors (SSRIs), venlafaxine (a selective norepinephrine reuptake inhibitor or SNRI) and the newer antidepressants bupropion, mirtazapine, moclobemide are all relatively safe in the elderly. They have lower anticholinergic side effects than older antidepressants and are thus well tolerated by patients with cardiovascular disease. SSRIs may cause nausea, dry mouth, insomnia, somnolence, agitation, diarrhoea, excessive sweating, and, less commonly, sexual dysfunction. [31]. As age advances, the renal function gradually decreases and this may increase the risk of elderly patients developing hyponatremia secondary to a syndrome of inappropriate antidiuretic hormone(SIADH) secretion. This syndrome is more common in patients receiving SSRIs and venlafaxine and on an average about $10 \%$ of patients 
may develop this [33]. The risk of gastrointestinal bleeding increased in patients receiving SSRIs, more so in individuals with a history of peptic ulcer or in those who receive non-steroidal anti-inflammatory drugs(NSAIDS). Fluoxetine is not preferred in elderly people with depression because of its long half-life and prolonged side effects. Among the SSRIs, paroxetine has the greatest anticholinergic effect and hence not preferred in the elderly [1]. Citalopram, escitalopram, sertraline, venlafaxine, mirtazapine, and bupropion have the lowest potential for drugdrug interactions whereas fluoxetine, paroxetine, and fluvoxamine have higher risks of drug-drug interactions [34]. Tricyclic antidepressants have potential for side effects such as postural hypotension, which can contribute to falls and fractures, cardiac conduction abnormalities, and anticholinergic effects, hence are no longer considered first-line agents in elderly patients. Other side effects of tricyclic antidepressants include delirium, urinary retention, dry mouth, and constipation. Hence they are considered as second line agents. Even then, they cannot be used in elderly patients with comorbid conditions like dementia, cardiovascular disease and parkinsonism because they can be worsened by tricyclic antidepressants [34].

Dementia, Parkinson's disease, and cardiovascular problems which are commonly seen is aged population can be worsened by a tricyclic antidepressant. If at all one decides to put the patient on tricyclic antidepressants as a second-line medication, nortriptyline and desipramine are the best choices as they have less anticholinergic side effects [35]. It is advisable that ECG and postural blood pressure are recorded before putting the patient on tricyclic antidepressants. Periodic blood level estimation of antidepressants is essential since tricyclic antidepressants blood level can be high despite low doses in patients who are slow metabolisers [1].

Monoamine oxidase inhibitors are not recommended for treatment of depression in elderly because of their high adverse effect profile and drug-drug interactions.

\section{Dosage schedule:-}

The usual recommended dose for elderly patient is half of the dose prescribed for a younger adult [1]. This is mainly to reduce adverse effects as elderly are more prone for adverse effects because of the changes in the physiological functions, concurrent medications and drug interactions. The present day recommendation is to increase the dose regularly at 1-2 week intervals as tolerated by the patients so that an average therapeutic dose is reached within a month [36]. If there is no improvement after a month, dose can be increased further till a clinical improvement, intolerable side effects or the maximum recommended dose is reached. Periodic follow-up to assess the patient response and side effects are essential part of the management.

\section{Recent advances in pharmacotherapy:-}

Newer drugs such as duloxetine and desvenlafaxine have shown to be effective in the management of depression in the elderly $[37,38]$. However, the available data is insufficient to try these drug in aged population and more studies are needed before considering these drugs. Another agent, methylphenidate is also being used in elderly patient with depression which has shown beneficial effect in controlling depressive symptoms, fatigue and apathy [39].

Among atypical antipsychotics aripiprazole and risperidone when used as adjuvant therapy in the treatment of depression in elderly showed some promise [40,41]. These are tried when there is an incomplete response to standard antidepressant therapy. While prescribing the atypical antipsychotics one has bear in mind the problems in older patients such as extrapyramidal symptoms, sedation, weight gain, dyslipidemia and diabetes mellitus associated with them. However, atypical antipsychotics may be an effective treatment for severe and refractory depression in elderly who fail to respond to antidepressants.

\section{Electroconvulsive therapy:-}

Electroconvulsive therapy(ECT) is an effective treatment for depression, which is safe and well tolerated. In elderly depressive patients ECT has been associated with better treatment outcomes and fewer side effects than pharmacotherapy [42]. In case of psychotic or severe depression, ECT followed by antidepressant therapy is sufficient and one can avoid antipsychotic medication and their associated side effects [1].

\section{Conclusion:-}

Elderly individuals with major depression is a common and growing problem that requires careful management. Due to physiological changes in the elderly selection of drug and its dose is real challenge to the treating physician. This is further complicated by the comorbid conditions and medication used to treat them leading to drug-drug 
interactions. However, with available drug and ECT one can effectively treat depression in the elderly. Proper selection of the drug and its dosage are very important for effective management of depression.

1. Canadian Coalition for Seniors' Mental Health. National guidelines for seniors' mental health: The assessment and treatment of depression. Toronto, ON: Canadian Coalition for Seniors' Mental Health; 2006. Accessed 24 September 2010. www.ccsmh.ca/en/guidelinesUsers.cfm.Blazer D, Williams CD. Epidemiology of dysphoria and depression in an elderly population. Am J Psychiatry 1980;137:439-444.

2. Murray CJ, Lopez AD. Evidence-based health policy--lessons from the Global Burden of Disease Study. Science. 1996; 274:740-743

3. Murray CJL, Lopez AD, editors. The Global Burden of Disease: A Comprehensive Assessment of Mortality and Disability from Diseases, Injuries, and Risk Factors in 1990 and Projected to 2020. Cambridge, MA: Harvard University Press; 1996

4. Korten NC, Comijs HC, Lamers F, Penninx BW. Early and late onset depression in young and middle aged adults: differential symptomatology, characteristics and risk factors? J Affect Disord. 2012;138(3):259-67

5. Gallo JJ, Anthony JC, Muthén BO. Age differences in the symptoms of depression: A latent trait analysis. J. Gerontol. 1994;49: P251-64

6. Christensen H, Jorm AF, Mackinnon AJ, Korten AE, Jacomb PA, et al. Age differences in depression and anxiety symptoms: A structural equation modelling analysis of data from a general population sample. Psychol. Med. 1999; 29:325-39

7. Butters MA, Whyte EM, Nebes RD, Begley AE, Dew MA, et al. The nature and determinants of neuropsychological functioning in late-life depression. Arch. Gen. Psychiatry. 2004; 61:587-95

8. Fiske A, Wetherell JL,Gatz M. Depression in Older Adults. Annu Rev Clin Psychol. 2009; 5: 363-389

9. Kendler KS, Gatz M, Gardner CO, Pedersen NL. A Swedish national twin study of lifetime major depression. Am. J. Psychiatry. 2006; 163:109-14

10. Kendler KS, Gatz M, Gardner CO, Pedersen NL. Age at onset and familial risk for major depression in a Swedish national twin sample. Psychol. Med. 2005; 35:1573-9

11. Tiemeier H. Biological risk factors for late life depression. Eur. J. Epidemiol. 2003; 18:745-50

12. Butters MA, Becker JT, Nebes RD, Zmuda MD, Mulsant BH, et al. Changes in cognitive functioning following treatment of late life depression. Am. J. Psychiatry. 2000; 157:1949-54

13. Alexopoulos GS. Depression in the elderly. Lancet. 2005; 365:1961-70

14. Schweitzer I, Tuckwell V, O'Brien J, Ames D. Is late onset depression a prodrome to dementia? Int. J. Geriatr. Psychiatry. 2002; 17:997-1005

15. Park JH, Lee SB, Lee TJ, Lee DY, Jhoo JH, et al. Depression in vascular dementia is quantitatively and qualitatively different from depression in Alzheimer's disease. Dement. Geriatr. Cogn. Disord. 2007; 23:67-73

16. Reijnders JS, Ehrt U, Weber WE, Aarsland D, Leentjens AF. A systematic review of prevalence studies of depression in Parkinson's disease. Mov. Disord. 2008; 23:183-9

17. Hettema JM, Kuhn JW, Prescott CA, Kendler KS. The impact of generalized anxiety disorder and stressful life events on risk for major depressive episodes. Psychol. Med. 2006; 36:789-95

18. Andreescu C, Lenze EJ, Dew MA, Begley AE, Mulsant BH, et al. Effect of comorbid anxiety on treatment response and relapse risk in late-life depression: controlled study. Br. J. Psychiatry. 2007; 190:344-9

19. Manber R, Edinger JD, Gress JL, San Pedro-Salcedo MG, Kuo TF, Kalista T. Cognitive behavioral therapy for insomnia enhances depression outcome in patients with comorbid major depressive disorder and insomnia. Sleep. 2008; 31:489-95

20. Nolen-Hoeksema S, Davis CG. "Thanks for sharing that": Ruminators and their social support networks. J. Pers. Soc. Psychol. 1999; 4:801-14

21. Fiske A, Gatz M, Pedersen NL. Depressive symptoms and aging: The effects of illness and non-health related events. J. Gerontol. B Psychol. Sci. Soc. Sci. 2003;58: P320-8

22. Mojtabai R, Olfson M. Major depression in community-dwelling middle-aged and older adults: Prevalence and 2-year and 4-year follow-up symptoms. Psychol. Med. 2004; 34:623-34

23. Hendrie HC, Albert MS, Butters MA, Gao S, Knopman DS, et al. The NIH Cognitive and Emotional Health Project: Report of the Critical Evaluation Study Committee. Alzheimers Dement. 2006; 2:12-32

24. Bostwick JM, Pankratz VS. Affective disorders and suicide risk: A reexamination. Am. J. Psychiatry. 2000; 157:1925-32.

25. Conwell Y, Brent D. Suicide and aging I: Patterns of psychiatric diagnosis. In: Pearson JL, Conwell Y, editors. Suicide: International Perspectives. Springer; New York: 1996. pp. 15-30 
26. MacArthur Initiative on Depression and Primary Care. Patient health questionnaire. Hanover, NH: MacArthur Initiative on Depression and Primary Care; 2012. Available from:www.depressionprimarycare.org/clinicians/toolkits/materials/forms/phq9. Accessed 2017 May 11.

27. Kennedy SH, Lam RW, Nutt DJ, Thase ME. Treating depression effectively: applying clinical guidelines. 2nd ed. London, UK: Martin Dunitz, Ltd; 2004

28. Kessler RC, Berglund P, Demler O, Jin R, Merikangas KR, Walters EE. Lifetime Prevalence and Age-of-Onset Distributions of DSM-IV Disorders in the National Comorbidity Survey Replication. Arch Gen Psychiatry.2005: 62(6):593-602

29. Schneider LS, et al., editors. Diagnosis and treatment of depression in late life. Washington, DC: American Psychiatric Press; 1994. Results of the NIH Consensus Development Conference; pp. 181-244.

30. Reynolds C, Frank E, Kupfer DJ, et al. Treatment outcome in recurrent major depression. Am J Psychiatry. 1996; 153:1288-1292

31. Alexopoulos GS, Katz IR, Reynolds CF, et al. Pharmacotherapy of depressive disorders in older patients. The expert consensus guideline series: A postgraduate medicine special report. New York: McGraw-Hill; 2001.

32. Cole MG, Elie LM, McCusker J, et al. Feasibility and effectiveness of treatments for depression in elderly medical inpatients: A systematic review. Int Psychogeriatr 2000;12:453-461.

33. Kirby D, Harrigan S, Ames D. Hyponatraemia in elderly psychiatric patients treated with Selective Serotonin Reuptake Inhibitors and venlafaxine: A retrospective controlled study in an inpatient unit. Int J Geriatr Psychiatry 2002;17:231-237.

34. Baldwin RC, Chiu E, Katona C, et al. Guidelines on depression in older people: Practising the evidence. London: Martin Dunitz; 2002.

35. Baldwin RC, Chiu E, Katona C, et al. Guidelines on depression in older people: Practising the evidence. London: Martin Dunitz; 2002.

36. Roose SP, Sackeim HA, Krishnan KR, et al. Antidepressant pharmacotherapy in the treatment of depression in the very old: A randomized, placebo-controlled trial. Am J Psychiatry.2004;161:2050-2059.

37. Wise TN, Wiltse CG, Iosifescu DV, et al. The safety and tolerability of duloxetine in depressed elderly patients with and without medical comorbidity. Int J Clin Pract 2007;61:1283-1293.

38. Raskin J, Xu JY, Kajdasz DK. Time to response for duloxetine $60 \mathrm{mg}$ once daily versus placebo in elderly patients with major depressive disorder. Int Psychogeriatr 2008;20:309-327.

39. Hardy SE. Methylphenidate for the treatment of depressive symptoms, including fatigue and apathy, in medically ill older adults and terminally ill adults. Am J Geriatr Pharmacother.2009;7:34-59.

40. Steffens DC, Nelson JC, Eudicone JM, et al. Efficacy and safety of adjunctive aripiprazole in major depressive disorder in older adult patients: A pooled subpopulation analysis. Int J Geriatr Psychiatry 2010; article published online in advance of print $\quad$ on $9 \quad 2010$. Accessed,October,2010.http://onlinelibrary.wiley.com.ezproxy.library.ubc.ca/doi/10.1002/gps.2564/full.

41. Alexopoulos GS, Canuso CM, Gharabawi GM, et al. Placebo-controlled study of relapse prevention with risperidone augmentation in older patients with resistant depression. Am J Geriatr Psychiatry 2008;16:21-30.

42. Manly DT, Oakley SP, Bloch RM. Electroconvulsive therapy in old-old patients. Am J Geriatr Psychiatry 2000;8:232-236. 